\title{
XIX a. raštų, rašytų rytų aukštaičių tarme, veiksmažodžio morfologijos ypatumai
}

\author{
REGINA RINKAUSKIENĖ \\ Lietuvos edukologijos universitetas, T. Ševčenkos g. 31, LT-031111 Vilnius \\ El. paštas: regina.rinkauskiene@vpu.lt
}

\begin{abstract}
XIX a. lietuvių raštijos kalba nèra išsamiai tyrinèta. Šiame straipsnyje gilinamasi i XIX a. raštų, parašytų rytų aukštaičių tarme, morfologiją. Tam tikslui apžvelgiama keleto to meto raštijos atstovų - Mykolo Cerausko, Lauryno Bortkevičiaus, Henriko Balevičiaus, Mykolo Smolskio, Tado Lichodzejausko, Kazimiero MichnevičiausMikèno, Antano Kitkevičiaus - religinių tekstų kalba. Daugiausia dėmesio skiriama veiksmažodžio morfologijai. Aptariami rasti archajiški ir tarminiai veiksmažodžiai bei jų formos, analizuojami pasitaikantys kamienų mišimo atvejai.
\end{abstract}

Raktažodžiai: XIX amžius, lietuvių religiniai raštai, rytų aukštaičiai, morfologija, veiksmažodis

XIX a. buvo sprendžiama bendrinès kalbos ir tarmès santykio problema. Tendencijų derinti žemaičių ir aukštaičių tarmes randame Simono Daukanto darbuose, ieškoti vidurinès tarmès ragino Laurynas Ivinskis. Bendros, visiems lietuviams suprantamos kalbos kūrimu rūpinosi Antanas Baranauskas $[8,180]$. XIX a. pradžioje, be žemaitiškų raštų, ėmè rodytis ir rytų aukštaičių tarmès šnektomis besiremiančių raštų. Daugiau ar mažiau laikydamiesi šios tarmès tada raše Antanas Strazdas, Valerijonas Ažukalnis, Kajetonas Aleknavičius, Pranas Savickas, Mykolas Smolskis, Mykolas Cerauskas ir kiti [3, 198]. Vis delto iki baudžiavos panaikinimo lietuviškai rašẻ daugiausia tik kaimo ir mažų miestelių kunigai, kurie rūpinosi išleisti prastuomenei pačias reikalingiausias lietuviškas religines knygas, nes turtingesnieji lietuviškai beveik nekalbèjo.

Aptariant XIX a. pradžios - XIX a. vidurio raštų, parašytų rytų aukštaičių tarme, veiksmažodžio morfologiją, remiamasi šiais tuo metu pasirodžiusiais darbais: Mykolo Cerausko knygelèmis Kozonis padekkavonès (1803), Senas katekizmas (1803), Lauryno Bortkevičiaus giesmių knygele Giesmès apie keturiolika staciju (1810), Mykolo Smolskio knyga Uvogos apie išganyma dūšios (1823), Tado Lichodzejausko pamokslu Gailus atminimas... (1841), Antano Kitkevičiaus lietuviškomis giesmėmis knygoje Hymny ojców świętych (1848), Henriko Balevičiaus knygele Keliavedys (1857) ir Kazimiero Michnevičiaus-Mikėno knyga Šventas Izidorius artojas (1859). 
Religinių veikalų autoriai nėra tos pačios patarmès atstovai (1), todèl nesigilinama $\mathfrak{i}$ specifinius patarmių požymius. Minètų autorių darbuose aiškiai jaučiama rytų aukštaičių tarmès ịtaka, nors neišvengta ir tam tikrų netolygumų (2).

Kaip žinome, rytų aukštaičių skiriamoji ypatybė yra dvigarsių an, am, en, em ir balsių $a$, e atliepimas $u n, u m$, in, im ir $u, i$. Visi minèti dèsningumai atsispindi šių autorių darbuose:

- Vietoj dvigarsio an - dvigarsis un: brungiaufias $16_{21}$; wundeni $7_{6}$ (MC1 (3)); kuntribi $237_{10}$ (AK); atsirunda $13_{25}$; tunkidawa $20_{3}$ (KMM); reyki kuntribes $81_{7}$ (MS); aptunka $17_{26}$; atrunda $15_{2}(\mathrm{TL})$; aptunkidami $107_{11}(\mathrm{LB})$; parfigunda $93_{21}(\mathrm{LB})$;

- Vietoj dvigarsio am - dvigarsis um: umżyną (4) $14_{25}$ (MC1); umżynu $4_{12}$ (MC2); skumbeja $23_{26}$ (KMM); unt umżiu $28_{17}$ (MS);

- Vietoj dvigarsio en - dvigarsis in: giwintu $5_{24}$; pinkti $12_{1}$ (MC1); fzwinti pamoksfley $4_{3}$ (MC2); kintejó 236 ${ }_{16}(\mathrm{AK})$; giwintumaj $12_{11}$ (KMM); kincziam $82_{14}$; perźingiou $120_{13}$ (MS); nużingia $15_{1}$ (TL); giwindami 30 ${ }_{4}(\mathrm{LB})$; nużingtu $60_{5}(\mathrm{HB})$; pafkinda $15_{9}$ (LB);

- Vietoj dvigarsio em - dvigarsis im: iżtimptu $58_{17}$; iżtimpinieja $58_{4} ;(\mathrm{HB})$;

- Vietoj balsio $q$ - balsis u: pedu $16_{19}$; cnatu $16_{19}$ (MC1); giedotum szwintu potéri $229_{13}$ (AK); szimtu duoti 9 ${ }_{26}$; drusiej 36 $36_{3}$ (KMM); abżabuła 69 ${ }_{14}$; inkus $80_{6}$ (MS); pagrużina $15_{1}$ (TL); nusgusk $51_{11}$; tussie $18_{12}$ (HB);

- Vietoj balsio e - balsis $i$ : terp fawi $7_{26}$ (MC1); paemis $235_{13}$ (AK); tikru łajmi (vienaskaitos galininkas) $6_{19}(\mathrm{KMM})$; esam girtibey inmirki $30_{2}(\mathrm{MS})$; uzmigis $39_{10}$; atfigrisz $49_{6}(\mathrm{LB})$.

\section{VEIKSMAŽODIS}

Apžvelgdami rytų aukštaičių tarme rašytų raštų veiksmažodžio ypatumus aptarsime keletą dèsningumų.

Labai retai vartojamos būtojo dažninio laiko veiksmažodžių formos. Z. Zinkevičiaus [6, 356] nuomone, senuosiuose raštuose buvo išsiverčiama su būtuoju kartiniu laiku, jo formas pakartojant ar sustiprinant tam tikrais prieveiksmiais, pvz., dažnai, tankiai. T.Lichodzejausko darbe rasta tik viena tokia forma (razdawat' $11_{9}$ ), M. Cerausko ir M. Smolskio - taip pat tik po vieną (dodawey $32_{7}(\mathrm{MC} 1)$; gułedawa $45_{15}(\mathrm{MS})$ ). L. Bortkevičiaus knygoje yra dvi būtojo dažninio laiko formos: eydawa $55_{9}$; kabiedawa $59_{20}$; H. Balevičiaus ir A. Kitkevičiaus - nè vienos. Vienintelis K. Michnevičius-Mikènas vartoja būtojo dažninio laiko formas: rasdawej $83_{14}$; pakełdawa $20_{4}$; apsiejdawa $13_{10}$; tunkidawa $20_{3}$.

Visuose tekstuose gausu skolinių (slavizmų): abczistik $72_{16}$; btagastawijem $67_{12}$; pamislik $20_{2}(\mathrm{HB})$; kriwidija $17_{18}$; prigatawoja $16_{13}$ (TL); pakorofi $25_{18}$; szienawok $16_{11}$; dabokites $24_{10}$; prociawoja $23_{39}$ (MC1); fzenawokit $16_{17}$; krywidiji $15_{29}$ (MC2); dumoja $16_{19}$; iszkoloja $30_{3}$ (KMM); buntawojas $22_{6}$; niesidumoju $87_{17}$; korok $20_{16}$; procawoiam $123_{27}$; welitumem $59_{9}$ (MS); té ulojam $235_{20}$; uloi $237_{12}$; uloi $239_{3}$ (AK); apfudije $101_{3}$ (LB).

(1) Mykolas Cerauskas ir Laurynas Bortkevičius pagal kilmę yra rytų aukštaičiai panevėžiškiai, Henrikas Balevičius ir Tadas Lichodzejauskas - rytų aukštaičiai uteniškiai, Mykolas Smolskis ir Antanas Kitkevičius - rytų aukštaičiai anykštènai. Apie Kazimiero Michnevičiaus-Mikèno tarmę sunku tiksliai ką nors pasakyti. Z. Zinkevičiaus $[8,183]$ nuoroda, kad minètasis autorius kilęs nuo Anykščių, nieko tiksliai nepasako, nes Anykščiu apylinkėse gali būti kalbama tiek anykštenų, tiek uteniškių, tiek širvintiškių patarme.

(2) Nè vienas XIX a. religinio turinio veikalas nebuvo parašytas viena kuria nors tarme; visuose pasitaikydavo ịvairių tarmių ypatybių.

(3) Pagal pirmąją vardo ir pavardès raidę santrumpomis žymimi veikalų autoriai.

(4) Nosinès raidès, nors ir nenuosekliai, rašomos tik M. Cerausko abiejuose darbuose. 


\section{TARMINĖS IR ARCHAJIŠKOS VEIKSMAŽODŽIŲ FORMOS}

Visų autorių darbuose užfiksuota tarminių tariamosios nuosakos pirmojo asmens formų: biegczie $11_{2}$; apsipilczie $12_{13}(\mathrm{HB})$; dekawoczia $17_{32}$; garbinczia $12_{8}$; paźinćia $12_{8}(\mathrm{MC} 1)$; praplatinczia $2_{9}$ (MC2); kłausczia $5_{14}$; palikczia $72_{6}(\mathrm{KMM})$; gałeczia $11_{12}$; gałecziu $121_{6}(\mathrm{MS})$ ir t. t. M. Smolskio knygoje vienaskaitos pirmojo asmens formos nevienodos: gałeczia išlaikiusi senesnę galūnę; gałecziu, saugoczius - tokios formos žinomos tik žemaičių tarmès plote [6, 363]; saugoczios - tokios formos užrašytos uteniškių tarmès šnektose, kurios yra netoli anykštėnų (Debeikiai, Vyžuonos). Čia reikètų paminèti ir M. Cerausko darbe rastą formą te notftoia $28_{21}$. Idomus kontrakcijos pavyzdys: priešdẻlis ne + priešdèlio at- balsis $a=$ no. Daug daugiau tokių pavyzdžių būtų galima rasti senuosiuose XVII ir XVIII amžiaus

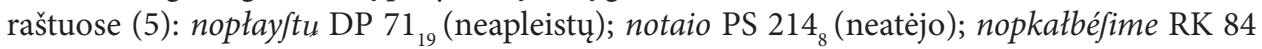
(neapkalbėsime).

Rasta nemažai sangrąžinių veiksmažodžių pilnųjų bendraties formų: wities $10_{14}$; wiesties $69_{9}$; linkties $72_{12}$; artinties $15_{13}$; turieties $61_{10}$; statities $69_{10}(\mathrm{HB})$; dżiaukties $10_{7}(\mathrm{TL})$. A. Kitkevičiaus giesmėse rasta bendraties formų su pridėtinèmis dalelytėmis: papjautén $241_{15}$; gimditén $233_{6}$. Tokios formos, Z. Zinkevičiaus $[6,433]$ duomenimis, užrašytos apie Kupiškị, taigi, galima sakyti, netoli A. Kitkevičiaus gimtųjų vietų. Tokių pat bendraties formų užfiksuota ir apie Vidiškius (6). M. Smolskio knygoje rasta viena neịprasta bendraties forma - niekrimstis (7) $49_{22}$. Tai priešdèlinis veiksmažodis, o rytinėse lietuvių tarmèse priešdèliniai sangrąžos veiksmažodžiai sangrąžos dalelytę turi po priešdèlio, tik labai retais atvejais būna kitaip $[1,53]$. Rasta ir sutrumpejusių bendraties formų: sugaut' $69_{7}$; dribt' 53; nupult' $51_{8}$; issilinkt 43 ; intżingt $56_{15}$ (HB); iżbiekt' $15_{1}$; palikt $21_{5}(\mathrm{TL})$. Pastebèta rašybos nevienodumų: kartais žymimas, kaip galima spèti, paskutinio priebalsio minkštumas (numirt' $71_{23}$; nukarat' $24_{4}(\mathrm{HB})$ ), kartais nežymimas (turet $48_{11}(\mathrm{HB})$; but $14_{7}(\mathrm{MC} 2)$; atłayst $118_{30}$ (LB); pamest $127_{11}$; ażmuszt $24_{21}$ (MS)), nors rytų aukštaičiai, nukritus priešakinès eilès balsiui, čia visada taria tik minkštąji priebalsị.

Rasta labai daug sutrumpëjusių formų, atsiradusių šalinant paradigmos asimetriją, t. y. ìvairių veiksmažodžio asmenuojamų formų dvivokalès galūnès yra pakeistos vienavokalèmis (8) [5, 224]: troksztam 15 ${ }_{12}$; bukit' $16_{24}$; razdawat' $11_{9}$; giwinkit' $16_{25}$ (TL); razdawat' $11_{9}$ (HB); inżimekim 47 ${ }_{12}$; pracawokit $65_{6}$ (MS); sustokim 234 ${ }_{8}$; pagaukit $241_{11}$ (AK); ażumirsztam $22_{15}$; prijuntat $18_{12}$ (KMM); fkeytam $8_{12}$ (MC2); sweykinam $116_{23}$ (LB) ir t. t.

Dviejų aptariamų autorių (K. Michnevičiaus-Mikėno ir M. Smolskio) darbuose vartojami siekiniai: ejni atsiiłsetu $47_{21}$ (KMM); ypač jų gausu M. Smolskio knygoje: eytumey wogtu $95_{16}$; eydami gułtu $9_{21}$; eydams gułtu $43_{6}$; eynunt gułtu $47_{22}$; nuweja gułtu $57_{11}$; nuweia gułtu $99_{12}$; ateys suditu $108_{24}$; eytumei razbaious daritu $95_{17}$. Ši ypatybè būdinga anykštènams ir kupiškènams, o M. Smolskis ir K. Michnevičius-Mikẻnas kaip tik yra kilę iš Anykščių apylinkių. Dabartiniu metu siekiniai jau gana reti kupiškẻnų, anykštenų ar panevėžiškių plote. Bendrinèje kalboje siekinị pakeitè tikslo bendratis: Išéjo medžiotų = išéjo medžioti $[4,279]$.

Rasta labai įdomių liepiamosios nuosakos formų: pagimiślik $73_{3}$; prigiprask $85_{23}$; niegi apteysk $121_{8}$; pagisiskubink $31_{24}$. Dalelytė gi yra ịterpta tarp priešdèlio ir šaknies. Tokių formų rasta tik M. Smolskio knygoje.

(5) Pavyzdžiai imti iš $[6,126]$.

(6) Vidiškiai yra rytų aukštaičiu širvintiškių plote.

(7) Atitinka formą nesikrimsti.

(8) Formuluotè galūnių sandaros asimetrijos šalinimas, arba dvivokaliu galūniu keitimas vienavokalèmis, insigali kalbotyroje vietoje paradigmos išlyginimo. 
Rasta nemažai atematinio asmenavimo liekanų, ypač veiksmažodžio būti: eśmi $35_{10}$; eśmu $72_{1}$; esti $52_{9}(\mathrm{HB})$; eafti $14_{4}$; efmi $18_{29}$; efme $12_{4}$; miegtj $25_{30}$ (MC1); nie efti $15_{29}$ (MC2); esti $38_{9}$; esti $38_{11}$ (KMM); esmi $19_{16}$; efte $44_{10}$ (LB); esti smertelnam grieki $23_{6}$; katrie baymiey esti $29_{10}$ (MS); esmu uiekałtas 67, nieesmu Ucznius $77_{29}$ (MS). Forma esmu greičiausiai laikytina perdirbiniu, nes paliekamas iš atematinio asmenavimo $m$, bet jau rašoma tematinio asmenavimo galūne $-u[7,104]$. M. Smolskio knygoje rasta kitokių veiksmažodžio gimti, gimsta, gime esamojo laiko formų, pavyzdžiui: giema $82_{11}$; giemam $18_{16}$. Rasta būsimojo laiko daugiskaitos pirmojo ir antrojo asmens formų su atematinio asmenavimo galūnèmis: dasistosmia 17 (TL); atrasma $22_{25}$; ne prażusma $76_{21}$; padarista $59_{2}(\mathrm{KMM})$; sugriszma $32_{9}$; iszkisma $82_{29}$; kista $83_{16}$; praputsta $27_{10}$; procawosma $125_{16}$; nienoresta $100_{1}$ (MS).

\section{Tarminiai ir archajiški veiksmažodžiai}

Dabartinejje kalboje jau nežinomi ir nebevartojami veiksmažodžiai blazgauti, blazgauja, blazgavo (negražiai kalbėti) (9): błazgauja $45_{2}$; šykštauti, šykštauja, šykštavo (šykštèti): ne sziksztawa $50_{19}$; naudauti, naudauja, naudavo (turèti naudą, pelnyti): naudautis $68_{15}$; žudinti, žudina, žudino (žudyti): prażudinsi $65_{16}$; laikinti, laikina, laikino (palikti, nesuvartoti): pałaykinti $31_{7}$; vienoti, vienoja, vienojo (vienyti): suwienos $72_{5}$. Visi šie veiksmažodžiai pavartoti K. Michnevičiaus-Mikèno knygoje. M. Smolskio knygoje rasta tokių veiksmažodžių: troškauti, troškauna, troškavo. LKŽ duomenimis, jis dažniausias kupiškènų (10) plote: troszkaunam $4_{21}$; slobnuoti, slobnuoja, slobnavo: słobnoia $4_{14}$; pastarasis būdingas rytų aukštaičiams (LKŽ pateikta pavyzdžių iš uteniškių ir vilniškių šnektų: Slobnuoja ir slobnuoja vaikas, net baisu! Trgn (11); Slobnavo, verke kruvinom ašarom, kai sužinojo Klt) (12)); nuogti, nuogsta, nuogo (13) (eiti nuogyn): nogsta $6_{1}$; nogsti $120_{18}$; brozyti, brozija, brozijo (14): apibrozit $24_{15}$; nieapibrozija $54_{6}$; apibrozit $73_{16}$; brožyti, brožija, brožijo (varyti, guiti) (15): apibrożijey $38_{20}$; apibrożijou $51_{13}$; apibrożijam $54_{22}$; kalbasyti, kalbasija, kalbasijo (16) (kalbèti, šnekučiuoti): niesikałbasit $57_{28}$; šlovyti, šlovija, šlovijo (veiksmažodžio šlovinti sinonimas): apszłowit $79_{6}$; apszłowija $79_{12}$; apszłowija $79_{29}$; szłowis $32_{12}$; valyti, valija, valijo (17): priniewalit $93_{28}$; žyvyti, žyvija, žyvijo (maitinti, šerti, turèti naudos): żiwija $12_{29}$; krušinti, krušina, krušino (sutrinti, susmulkinti, sugrūsti): niesukruszintu 3 ; susikruszint $69_{19}$; puikinti(s), puikina(si), puikino(si) (būti išdidžiam, didžiuotis) (18): puykintis 101 $1_{5}$;

(9) Šio veiksmažodžio nèra LKŽ, bet jo reikšmè nustatyta iš konteksto: Wirsta pikcziau galwija, kiejkia ir błazgauja pikcziau nuo prakejkta <...> 45

(10) M. Smolskis ilgą laiką buvo Kupiškio parapijos dekanas, vadinasi, galèjo prisirinkti tokių formų.

(11) Tauragnai, Utenos r. (rytų aukštaičių uteniškių patarmè).

(12) Kaltanènai, Švenčionių r. (rytų aukštaičių vilniškių patarmè).

(13) LKŽ (www.lkz.lt) užfiksuota tik keletas sakinių iš J. Barono Rusų-lietuviu kalbu žodyno (1933) ir iš Dūkšto (Ignalinos r.) bei Rodūnios (Baltarusija) šnektų.

(14) LKŽ pateikia reikšmę sunkiai nešti, tačiau M. Smolskio veikale šis veiksmažodis turi kitą reikšmę: „<...> ir teys griekeys sunkiey Diewa nieapibrozija ir nenusidieja “ $54_{5-6}$; ,weli wis nutrotit nieg Diewu apibrozit" $73_{15-16 \text {. }}$ Reikšmé galètų būti $u \check{z} r u \bar{s} t i n t i$.

(15) Šis veiksmažodis yra veiksmažodžio brozyti sinonimas: „<...> Diewas, katru griekeys sawa tiek kartu apibrożijey“ $38_{19-20} ;$, $<\ldots>$ tawi Wieszpatie Diewie, tiek kartu griekey mana apibrożijou“ $51_{11-13}$.

(16) Užrašytas iš Zarasų ir Panemunèlio vietovių.

(17) Šis veiksmažodis gali turèti labai daug reikšmių, bet šioje knygoje vartojamas reikšme priversti, atves$t i$ („pakusa niegałeja unt grieku tawi priniewalit“).

(18) L. Bortkevičiaus knygoje ta pačia reikšme vartojamas veiksmažodis puikauti, puikauja, puikavo (ne puykauje 104 $)_{4}$. 
puykinous $120_{15}$; tuskinti, tuskina, tuskino (belsti, judinti, budinti): tuskink $76_{11}$; skubyti,

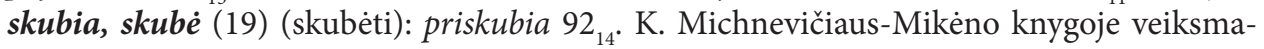
žodžio bendraties imti ir iš jos padarytų formų šaknies vokalizmas gali būti tiek su $e$, tiek su $u$, pvz.: pajumti $9_{26}$; ne nujema $22_{23}$; apijame $32_{15}$; pajumtu $35_{2}$; pajumti $38_{8}$; jumti $39_{11}$; prijame $39_{19}$; ażujame $41_{10}$; pajeme $44_{5}$; prijemdawa $44_{10}$; pajemtu $60_{16}$; prijeme $60_{17}$; jema $61_{2}$; jumk $67_{15}$; prijamej $67_{16}$; prijema $68_{19}$; prijumti $70_{2}$; atajeme $71_{13}$. Rastas retas veiksmažodis žabaldyti, žabaldžia, žabalde (20) (žabalti): abżabaldżia 93 ${ }_{21}$; taip pat rasta tarminių veiksmažodžių mokyti ir plauti formų: mokinti, mokina, mokino: pasimokinti $54_{1}$; plausti, plaudžia, plaude: apsipłaustumaj $64_{17}$.

Daugelis autorių vartoja veiksmažodžio taryti, taro, tare் (21) (tarti) formas: isztarit' $11_{21}(\mathrm{HB})$; ne isztarisi $9_{20}$; isztarisi $9_{23}$; isztariti $15_{26}$; tarik $33_{18}$; isztaritu $33_{20}$; isztaritumaj $34_{24}$; tariti $36_{3}$; ażutariti $41_{25}$; isztariti $57_{21}(\mathrm{KMM})$; usztarik $38_{9}$; asztarisiu $78_{9}$; nieusztaris $95_{23}$ (MS). Taip pat dažnas tarminis veiksmažodis reikti, reikia, reiké: reykie $12_{32}$ (MC1); rejks $14_{11}$; rejktu $72_{5}$; rejks $84_{8}$; ne rejkia $3_{11}$; ne rejkia $3_{12}$; rejkia $4_{2}(\mathrm{KMM})$.

\section{KAMIENŲ MIŠIMAS}

Rasta labai daug sumišusių esamojo ir būtojo kartinio laiko kamienų formų.

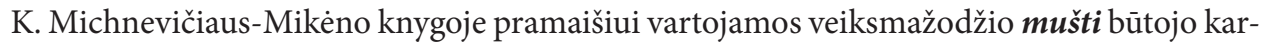
tinio laiko formos rodo, kad šis veiksmažodis turi dvejopą būtojo kartinio laiko kamieną (mušè ir mušo - plg. bk mušé): ne muszia $13_{15}$; musza $45_{7}$; izsmuszia $45_{19}$; iszmusza $51_{22}$; ażumusza $63_{17}$; musza $67_{6}$. Veiksmažodžio ilsèti esamojo laiko forma yra ia kamieno ilsia $75_{6}$ (plg. ilsi); veiksmažodžio veizdèti esamojo laiko formos yra dvejopos: wejzda $10_{9}$ (=veizdo) ir wejzdi 18. Veiksmažodžio imti esamojo laiko formos svyruoja tarp a ir ia kamienų, pvz.: nujema $22_{23}$ ir jemia $65_{19}$. M. Smolskio knygoje rasta tokių sumišusių kamienų: beveik visi $i$ kamieno veiksmažodžiai turi dejopas formas, pavyzdžiui: norit $128_{27}$; noriat $77_{18}$; miłat $128_{26}$; turiat $100_{2}$; turim $12_{26}$; turiam $123_{13}$; niegalam $129_{11}$; niegalim $59_{15}$. Dvejopu šių veiksmažodžių formų rasta ir M. Cerausko knygoje: niemilat $14_{15}$; mili $7_{1}$; turem $9_{2}$; galat $5_{13}$ (MC2). Z. Zinkevičiaus nuomone [6, 342], aukštaičių tarmès plote $i$ ir i $i a$ kamienų formos yra vartojamos pagrečiui; minimos tokios vietovès: Anykščiai, Biržai, Dusetos.

Rasta kitokių esamojo laiko formų: girdžia (forma girdžia dažna kupiškėnų plote): girdżia 93 $3_{1}$; girdżiam $29_{26}$ (MS); girdźiat $16_{9}$ (MC2); rodžia: rodżia $12_{13}$; (HB) rodziame $20_{7}$; rodżia $103_{26}$ (MC1); mokia: mokia $17_{6}(\mathrm{HB})$; mokiu $3_{10}$ (MC1); mokia $15_{21}$ (KMM); mokia $18_{22}$; mokia $47_{19}$ (MS); pildžia: niepildżia $6_{13}$; iszpildżia $7_{11}$ (MS); skelda (22): skiełda 112 ${ }_{18}$ (MS); žūsta: źusta $5_{7}$ (KMM); gulsta: gutsta $44_{19}$ (KMM); rausta (veiksmažodis rausti, rausia, rausé): iszrausta (23) $7_{22}$ (KMM); pulsta: prapułsta $27_{10}$; plg. uszpoła $34_{4}$ (MS); junčia (veiksmažodis jausti, jaučia, jautè): junczia (24) $70_{10}$; jaute $6_{19}$; junte (25) $70_{14}$ (KMM); pykdžia: ażupikdżia

(19) Toks veiksmažodis užfiksuotas šiaurinejje Lietuvoje, ypač Kupiškio ir Rokiškio rajonuose.

(20) LKŽ duomenimis, toks veiksmažodis užrašytas iš Panevėžio r. Paįstrio šnektos, taip pat iš įvairių XX a. žodynų.

(21) Tokios šio veiksmažodžio formos, LKŽ duomenimis, yra užrašytos iš F. Kuršaičio žodyno (XX a.), E. Frenkelio Lietuvių kalbos etimologinio žodyno (XX a.), Lietuviškai-latviško žodyno (1929 m., sudarè J. Ryteris).

(22) Forma skelda užfiksuota tik XVIII a. žodynuose.

(23) Tokios esamojo laiko formos LKŽ pateiktos tik iš senųjų raštų.

(24) Tokia forma LKŽ pateikta iš Čiobiškio vietovès (rytų aukštaičiai).

(25) Greta vartojamos skirtingos būtojo kartinio laiko formos. 
$17_{3}(\mathrm{KMM})$; karaliauna: karalauni $70_{20}(\mathrm{HB})$; rinka (veiksmažodis rinkti, renka, rinko): surinki $51_{17}$ KMM. Tokia forma buvo užrašyta Zietelos tarmèje, kada esamojo laiko šaknies vokalizmas derinamas prie bendraties ir būtojo kartinio laiko [6, 338].

Rasta kito kamieno būtojo kartinio laiko formų: leidè: prałajde $16_{10}$; perłayde $27_{13}$ (KMM); apteydie $23_{26}$; atłeydie $88_{15}$ (MS); atłayde $96_{11}$ (LB); bruke: nubrukie $86_{11}$ (MS).

\section{IŠVADOS}

1. XIX a. pradžios - XIX a. vidurio raštuose, parašytuose rytų aukštaičių tarme, gausu rytų aukštaičių fonetikos ypatybių, kurias rodo rašyba: łunkidawa $20_{3}$ (KMM); unt umżiu $28_{17}$ (MS); nużingia 15 (TL); giwindami 30 $(\mathrm{LB})$; tussie $18_{12}(\mathrm{HB})$; paemis $235_{13}$ (AK) ir t. t.

2. XIX a. pradžios - XIX a. vidurio raštų rytų aukštaičių tarme veiksmažodis pasižymi archajiškais bruožais:

- rasta nemažai šiuo metu jau nevartojamų veiksmažodžių: taryti, taro, taré; žabaldyti, žabaldžia, žabalde; kalbasyti, kalbasija, kalbasijo; vienoti, vienoja, vienojo ir pan.

- rasta retų veiksmažodžio formų: liepiamosios nuosakos forma su dalelyte gi, įsiterpusia tarp priešdèlio ir šaknies (pagimiślik $73_{3}$; prigiprask $85_{23}$; niegi apłeysk $121_{8}$; pagisiskubink $31_{24}$ (MS); sangrąžinio priešdèlinio veiksmažodžio bendratis su sangrąžos afiksu žodžio gale (niekrimstis $49_{22}$ (MS)); atematinio asmenavimo formų (efmi $18_{29}$; efme $12_{4}$; miegtj $25_{30}$ (MC); esti 38 (KMM); katrie baymiey esti $29_{10}(\mathrm{MS})$ ); senųjų tariamosios nuosakos pirmojo asmens formų (apsipilczie 12 ${ }_{13}(\mathrm{HB})$; dekawoczia 17 ${ }_{32}$ (MC1); kłausczia $5_{14}$ (KMM); gałeczia $\left.11_{12} ; 121_{6}(\mathrm{MS})\right)$ ir t. t.

3. Gausu kamienų mišimo atvejų: ne muszia $13_{15}$; musza $45_{7}$ (KMM); norit $128_{27}$; noriat $77_{18}$ (MS); prałajde $16_{10}$ (KMM) apłeydie $23_{26}$; atteydie $88_{15}$ (MS); nubrukie $86_{11}$ (MS).

4. Labai dažnai vartojami ìvairūs skoliniai (slavizmai): abczistik $72_{16}$; pamislik $20_{2}(\mathrm{HB})$; prigatawoja $16_{13}$ (TL); pakorofi $25_{18}$; szienawok $16_{11}$ (MC1); dumoja $16_{19}$; iszkoloja $30_{3}$ (KMM); buntawojas 22 ; welitumem 59. $(\mathrm{MS})$; uloi 237 ${ }_{12}$; té ulojam $235_{20}$ (AK).

Gauta 20111010

Priimta 20111018

\section{Literatūra}

[1] KAUKIENĖ, Audronè. Sangrąžinių veiksmažodžiu istorija. Klaipèda: Klaipèdos universitetas, 2006.

[2] Lietuviu kalbos žodynas - elektroninè versija $w w w . l k z . l t$

[3] PALIONIS, Jonas. Lietuvių literatūrinès kalbos istorija. Vilnius: Mokslas, 1979.

[4] PAULAUSKIENÉ, Aldona. Lietuvių kalbos morfologija. Vilnius: Mokslo ir enciklopedijų l-kla, 1994.

[5] ROSINAS, Albertas. Latvių kalbos daiktavardžio linksniavimo sistema: sinchronija ir diachronija. Vilnius: Mokslo ir enciklopedijų leidybos institutas, 2005.

[6] ZINKEVIČIUS, Zigmas. Lietuvių dialektologija. Vilnius: Mintis, 1966.

[7] ZINKEVIČIUS, Zigmas. Lietuvių kalbos istorine gramatika. T. 2. Vilnius: Mokslas, 1981.

[8] ZINKEVIČIUS, Zigmas. Lietuvių kalbos istorija. T. 4: Lietuviu kalba XVIII-XIX a. Vilnius: Mokslas, 1990.

\section{Santrumpos}

AK - Antanas Kitkevičius

DP - Daukšos Postilè. Fotografuotinis leidimas. Kaunas, 1926.

HB - Henrikas Balevičius 
KMM - Kazimieras Michnevičius-Mikènas

LB - Laurynas Bortkevičius

MC1 - Mykolo Cerausko Senas Katekizmas

MC2 - Mykolo Cerausko Kozonis padekavonès

MS - Mykolas Smolskis

PS - Šyrwids Punktay sakimu (Punkty kazań). Teil I: 1629, Teil II: 1644. Litauisch und Polnisch mit Kurzer Grammatischer Einleitung Herausgegeben von Dr. Franz Specht. Göttingen, 1929.

RK - Katechismas Aba Pamokimas... Vntrukart iszspaustas Wilnivy 1605. Cituojama iš E. Sittingo perspausdinto teksto: Der Polnische Katechismus des Ladezma und die Anonymus von Jahre 1605 nach Krakauer Originalen... Interlinear Herausgegeben. Göttingen, 1929.

TL - Tadas Lichodzejauskas.

REGINA RINKAUSKIENĖ

\section{Peculiarities of verb morphology in the 19th century texts written in the Eastern Aukštaitian dialect}

\section{Summary}

The language of the 19th century Lithuanian writings has not been thoroughly researched. Thus, in this article, the morphology of the 19th century texts written in the Eastern Auštaitian dialect is analysed. The language of religious texts written by representatives of that century (Mykolas Cerauskas, Laurynas Bortkevičius, Henrikas Balevičius, Mykolas Smolskis, Tadas Lichodzejauskas, Kazimieras Michnevičius-Mikenas, and Antanas Kitkevičius) is reviewed. Attention is focused on verb morphology. The archaic and dialectal verbs and their forms are discussed, and cases of stem mixing are analysed.

Key words: 19th century, Lithuanian religious texts, Eastern Aukštaitian, morphology, verb 